Dicle University Journal of Engineering (DUJE)

web: http://dergipark.gov.tr/dumf

Araştırma Makalesi / Research

\title{
Kısmi En Küçük Kareler Yapısal Eşitlik Modelinin Yeraltı Suyu Kalitesinin Değerlendirilmesinde Kullanımı
}

\section{The Use of Partial Least Squares Structural Equation Model in the Evaluation of Groundwater Quality}

\section{Zeki Doğan', Hamza Yalçin',", İbrahim Yenigün ${ }^{3}$, A. Volkan Bilgili4}

${ }^{1}$ Harran Üniversitesi, Zootekni Bölümü, Şanlıurfa, zdogan@ harran.edu.tr

${ }^{2}$ Harran Üniversitesi, Zootekni Bölümü, Şanlıurfa, hyalcin@ harran.edu.tr

${ }^{3}$ Harran Üniversitesi, Mimarlık Bölümü, Şanlıurfa, brahimyenigun@ harran.edu.tr

${ }^{4}$ Harran Üniversitesi, Toprak Bilimi ve Bitki Besleme Bölümü, Şanlıurfa, vbilgili@ harran.edu.tr

\section{MAKALE BİLGILERİ}

Makale geçmişi:

Geliș: 27 Ekim 2020

Düzeltme: 2 Aralı 2020

Kabul: 2 Aralık 2020

\section{Anahtar kelimeler:}

su kalitesi, anyonlar, katyonlar, yapısal eşitlik modeli

\begin{abstract}
ÖZET
Bu araştırmada su kalitesi ikinci nesil çok değişkenli bir istatistik metodu olan Kısmı En Küçük Kareler Yapısal Eşitlik Modeli (KEKK-YEM) kullanılarak incelenmiștir. KEKK-YEM gözlenen değişkenlerden yola çıkıp doğrudan gözlemlenemeyen (latent) değişkenler arasındaki ilişkileri açıklamaya çalışır. KEKK - YEM modelinde kullanılan gözlenen su kalitesi faktörleri pH, TDS katyonlar $\left(\mathrm{Mg}^{2+}, \mathrm{Na}^{+}\right)$ve anyonlar $\left(\mathrm{HCO}_{3}^{-}, \mathrm{Cl}^{-}\right.$ve $\left.\mathrm{SO}_{4}^{+}\right)$. Çalışmada kullanılan KEKK-YEM modeli iki aşamada değerlendirilmiştir; ölçüm modelinin uygunluğu farklı uyum indisleri ile birinci aşamada değerlendirildikten sonra ikinci aşamada yapısal model değerlendirilmiştir. YEM model sonuçlarına göre, su kalitesi üzerinde katyonların $(\gamma=0.598, \mathrm{p}<0.05)$ anyonlardan $(\gamma=0.259, \mathrm{P}<0.05)$ daha etkili olduğu ve yine $\mathrm{pH}$ üzerinde katyonların $(\gamma=0.643, \mathrm{P}<0.05)$ anyonlardan $(\gamma=-0.512, \mathrm{P}>0.05)$ daha etkili olduğu tahmin edilmiștir. Su kalitesi varyansının $\% 65$ 'i $\left(\mathrm{R}^{2}=0.650\right)$ ve $\mathrm{pH}$ 'nin varyansının $\% 19.5$ 'i $\left(\mathrm{R}^{2}=0.195\right)$ anyonlar ve katyonlar tarafından açıklandığı görülmüştür. Sonuç KEKK-YEM'in su kalitesinin değerlendirilmesinde klasik çok değişkenli ve bazı önkoşullara sahip daha fazla örneğe ihtiyaç duyan geleneksel istatistiksel metotların yerine başarı ile kullanılabileceğini göstermiştir.
\end{abstract}

Doi: $10.24012 /$ dumf. 816469

\begin{tabular}{|c|c|}
\hline ARTICLE INFO & ABSTRACT \\
\hline Article history: & \multirow{5}{*}{$\begin{array}{l}\text { In this study, water quality was analyzed using the Partial Least Squares Structural Equation Model (PLS-SEM), } \\
\text { which is a second-generation multivariate statistical method. PLS-SEM explains the relationships between varia- } \\
\text { bles that cannot be directly observed using observed variables. The observed water quality factors used in PLS- } \\
\text { SEM model are pH, TDS; cations }\left(\mathrm{Mg}^{2+}, \mathrm{Na}^{+}\right) \text {; and the anions }\left(\mathrm{HCO}_{3}^{-}, \mathrm{Cl}^{-} \text {ve } \mathrm{SO}_{4}^{+}\right) \text {. The model used in the study } \\
\text { was evaluated in two stages; after the appropriateness of the measurement model was evaluated with different fit } \\
\text { indices in the first stage, the structural model was evaluated in the second stage. According to the results of the } \\
\text { PLS-SEM model, it was found that cations }(\gamma=0.598, \mathrm{P}<0.05) \text { were more effective than anions }(\gamma=0.259, \mathrm{P}<0.05) \text {, } \\
\text { and cations }(\gamma=0.643, \mathrm{P}<0.05) \text { was predicted to be more effective on pH than anions }(\gamma=-0.512, \mathrm{P}>0.05) \text {. It was } \\
\text { seen that } 65 \% \text { of the variance of water quality }\left(\mathrm{R}^{2}=0.650\right) \text { and } 19.5 \%\left(\mathrm{R}^{2}=0.195\right) \text { of the variance of pH were } \\
\text { explained by anions and cations. The result has shown that PLS-SEM can be used successfully instead of tradi- } \\
\text { tional statistical methods, which require more samples with some prerequisites and with classical multivariate } \\
\text { statistical techniques for the assessment of water quality. }\end{array}$} \\
\hline Received: 27 October 2020 & \\
\hline 2 December 2020 & \\
\hline Accepted: 2 December 2020 & \\
\hline $\begin{array}{l}\text { water quality, anions, cations, } \\
\text { structural equation model (PLS- } \\
\text { SEM) }\end{array}$ & \\
\hline
\end{tabular}

* Sorumlu yazar / Correspondence

Hamza YALÇİN

$\triangle$ hyalcin@harran.edu.tr 


\section{Giriş}

Yeraltı suyu hem içme hem de sulama amaciyla kullanılmaktadır. Yeraltı su kalitesini etkileyen faktörlerin takibi ve kontrolü sürdürülebilir bir yer altı suyu kullanımı için gereklidir. Düşük kaliteli veya kirlenmiş yeraltı suları doğrudan içme amaçlı veya sulama suyu olarak kullanıldıklarında dolaylı yollardan bitkilerden insanlara geçtiğinde farklı sağlık sorunlarına neden olabilir [1].

$\mathrm{Bu}$ amaçla yer altı suları arazi ve laboratuvar ortamında düzenli aralıklarla örneklenir, gözlemlenir ve sulardaki kirleticilerin konsantrasyonları belirlenir. Elde edilen farklı kalite parametrelerinin bir araya getirilmesi ile yeraltı sularının içme ya da sulama amacına uygunluklarının ortaya koyulmas1 amaciyla kaliteleri belirlenir [2]. Mevsimsel, yersel dağılımları ve farklılıkları korelasyon analizi, kümeleme analizi, faktör analizi, temel bileşenler analizi (PCA) gibi tek ve çok değişkenli istatistiksel yaklaşımlar ile sıkça ortaya koyulmuş ve araştırılmıştır [2], [3].

Kısmi en küçük kareler veya varyans tabanlı yapısal eşitlik modelleri (VT-YEM; partial least squares structural equation modeling-PLS-SEM) çok değişkenli ikinci nesil çok değişkenli analiz teknikleri olarak Wold (1975) tarafindan önerilmiș. VT-YEM modeli olarak bilinen, kısmi model yapılarını temel bileşenler analizi (TBA) ve kısmi en küçük kareler regresyonuyla birleștirilerek tahmin eden bir metottur. VT-YEM daha karmaşık modelleri çözümlemeye yönelik bir yaklaşım olarak düşünülmektedir [5].

İkinci nesil bir veri analiz tekniği olarak Yapısal eşitlik modellemesi (YEM), regresyon gibi doğrudan ölçülebilen bağımlı-bağımsız değişkenler arasındaki ilişskileri inceleyen birinci nesil istatistiksel tekniklere kıyasla, doğrudan ölçülemeyen değișkenler arasındaki ilișkilerin değerlendirebilir ayrıca her bir ilişki için farklı bir analize gerek duyulan regresyon analizlerinin aksine, değişkenler arasında belirlenen tüm ilișkilerin tek bir analizle ortaya konulabilmesi gibi üstünlüklere sahiptir [6]. Ayrıca YEM gözlemlenen (ölçülen) ( $\mathrm{pH}, \mathrm{SO}_{4}$ vs.) ve doğrudan gözlenmemiş gizil değişkenleri (latent yapılar) (su kalitesi, hava kirliliği vs.) beraber değerlendiren çok değişkenli bir teknik iken, geleneksel yöntemler sadece ölçülen değişkenler arasındaki ilişkileri analiz etmektedir [7]. YEM metodu ile parametre tahminlerini belirlemek için eşzamanlı çoklu denklemler çözülür ve YEM araştırmaciların ölçümlerinin kusurlu niteliğini ortaya çıkarmasına olanak tanır. Geleneksel yöntemler, ölçme işlemi hata olmadan gerçekleşirken, YEM açıkça hata belirtir [8].

YEM modeli farklı iki grup altında kullanılmıştır; Kovaryans tabanlı Yapısal eşitlik modellemesi (CB-SEM) ve varyans tabanlı yapısal eşitlik modellemesi olarak da bilinen Kısmi En Küçük Kareler Yapısal Eşitlik Modellemesi (VT YEM; PLS-SEM). VT-YEM tekniği tarafından önerilen örnek sayısı ve verinin normal dağılım göstermesi gibi önkoşullara sahip kovaryans tabanlı CB-SEM modeline bir alternatif olarak önerilmiştir [6]. Varyans tabanlı yapısal eşitlik modeli olarak da bilinen VT-YEM modeli CB-SEM modeline göre örnek dağılımındaki esneklik, daha az örnekle çalışabilme ve daha kompleks modellerin çözülebilmesi gibi bir takım avantajları olduğundan daha fazla tercih edilmektedir [9]. CBSEM verilerin kovaryans matrisini kullanır ve model parametrelerini tahmin etmek için sadece ortak varyansı kullanırken, VT-YEM varyans tabanlı bir model olarak toplam varyansı açıklar ve gizil bağımlı yapıya ait $\mathrm{R}^{2}$ değerlerini en büyük yapan katsayıları kestirir [10]. Bu avantajlarından dolayı VT-YEM metodu daha çok tercih edilmektedir. Bu çalışmada çok değişkenli normal dağılım gerektirmeyen ve az sayıda örnekle çalışabilen çok değişkenli istatistik metot olan VT-YEM yöntemi kullanılmıştır.

YEM modelinde, ölçüm değişkenleri (biçimlendirici ölçme modeli ve yansıtıcı ölçme modeli) ve yapısal değişkenler olarak ikiye ayrılır. Ölçme değișkenleri (dışsal model olarak da isimlendirilir) yakınsayana kadar iteratif olarak çalışır, gizil değişkenlerin (latent variables) yol katsayıları, güven aralıkları ve ilgili $\mathrm{R}^{2}$ değerleri elde edilir [7]. Gizil değişkenlere ait veriler sürekli verilerdir. Elde edilen bu değerler sayesinde gizil değişkenler arasındaki ilişkileri belirlemek amacıyla sıralı en küçük kareler regresyon (OLS) analizi uygulanır. Model kalite kontrolleri (AVE, VIF, HTMT, R ${ }^{2}$ vs.) yapıldıktan sonra nihai raporlama yapilir. 


\section{Kısmi En Küçük Kareler Yapısal Eşitlik Mo- dellemesi (VT-YEM)}

VT-YEM metodu gizil (Latent) değişkenler arasındaki ilişkiyi modelleyen yapısal eşitlik modeli olup 1980 yılında Wold tarafından geliştirilmiştir (Wold, 1980). Şekil 1 genel olarak bir PLS metodunu göstermektedir. VT-YEM gizil değişkenler (GD) ve bunların arasındaki bağlantılardan meydana gelen iç (inner) yapısal model ile ölçüm modeli olan dış (outer) model olmak üzere iki k1sımdan meydana gelmektedir. İç model kısmında gizil değișkenler arasındaki bağlantılar yol katsayıları (path coefficients; $P$ veya $\gamma$ ) ile; dış model ile göstergeler arasındaki ilişkilerin derecesi ise ağırlıklar (w)/yükler (1) ile gösterilir. Yol katsa- yıları gizil bağımlı değişkenlerin (endojen) üzerine gizil bağımsız değişkenlerin (eksojen) etkisini temsil eder [5].

VT-YEM'de genel olarak biçimlendirici (formative) ve yansitıcı (reflective) olmak üzere iki farklı ölçme modeli analiz edilebilir. Yansıtıcı modeller, gizil değişkenden başlayıp ölçülmüş değişkende sonlanan yollarla karakterize edilirken, biçimlendirici modellerde tersinedir ve yolun istikameti ölçülen değiş̧kenden gizil değişkene doğrudur. Yansitıcı modellerde ölçülen değişkenler gizil değişkenin etkisi olarak görülürken; biçimlendirici modellerde ölçülen değişkenler gizil değişkenlerin nedenleri olarak görülmektedir. VT-YEM modeli son zamanlarda yönetim, uluslararası yönetim, insan kaynakları,

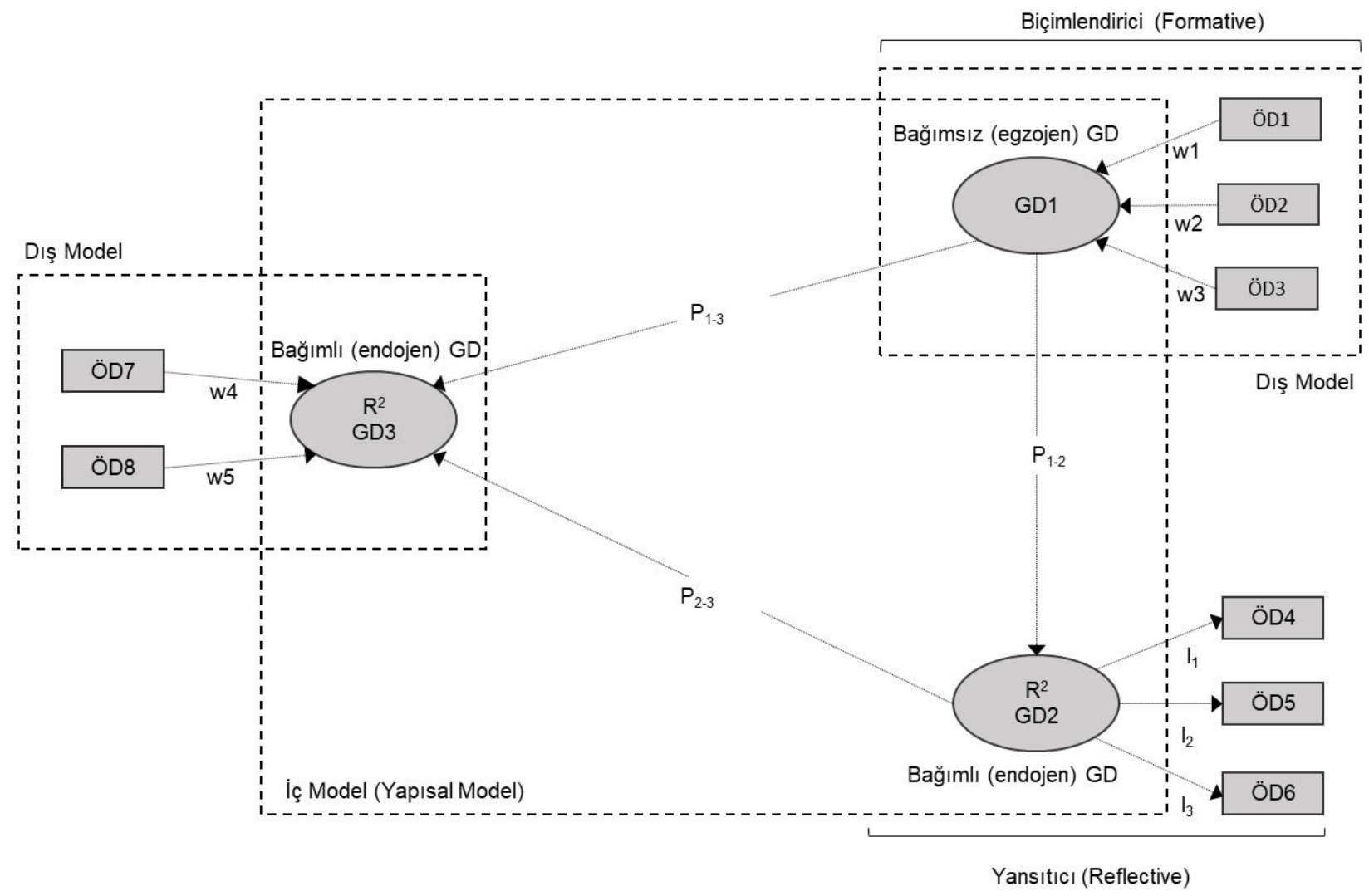

Şekil 1. VT-YEM Modeli; ÖD: Ölçülen değişkenler; GD: Gizil değişkenler; w: Ă̆ırlıklar; P: Yol katsayısı; l: Yükler (loading); $R^{2}$ : Endojen değişken(ler)e ait belirleme katsayısı.

Figure 1. PLS-SEM Model; ÖD: Measured variables; GD: Latent variables; w: Weights; P: Path coefficient; l: Loadings; $R^{2}$ : The coefficient of determination of the endogenous variable(s). 
market ve pazarlama, işletme, tedarik zinciri yönetimi gibi alanlarda kullanılmıştır [11]. Bahsedilen sosyal alanların haricinde VT-YEM modeli fen bilimleri alanlarında da kullanılmaya başlanmıştır [12].

Genel olarak bu çalışmanın amacı VT-YEM modelinin su kalitesinin belirlenebilirliğinde kullanılabilirliği test etmek ve bu alanda çok farklı ve yeni bir yaklaşım olarak elde edilen sonuçların yorumlanabilirliğini göstermektir. Çalışmada VT-YEM modeli mevcut bir veri üzerinde denenmiştir [13].

\section{Materyal ve Metot}

\section{Veri seti}

Makalede kullanılan veriler Viswanath vd. (2015)'den alınan veriler ile oluşturulmuştur. Makalede $\mathrm{SO}_{4}, \mathrm{HCO}_{3}$ ve $\mathrm{NO}_{3}$ değişkenlerinde yer alan " 0 " (sıfır) rakamları silinip ilgili yerlere ilgili değişkenin ortalaması yerleştirilmiştir. Parantez içleri $\mathrm{p}<0.05$ anlamlılık düzeyinde değerlendirilmiştir ve bu değer katsayının anlamlılığını ifade eder.

\section{Metot}

\section{Varyans Tabanlı Yapısal Eşitlik modellemesi (VT-YEM)}

VT-YEM ya da PLS-SEM yapısal eşitlik modelleri ailesinin bir üyesidir. İkinci jenerasyon çok değişkenli bir istatistik metodudur. Herman wold [14] tarafından geliştirilmiş olup normal dağılım şartı aramadığı için "yumuşak modelleme" olarak tarif edilmiştir. Dolayısıyla VT-YEM, parametrik olamayan bir yöntem olarak kabul görmüştür. Kovaryans tabanlı YEM'e göre daha az örneklem istemesi, normal olamayan bir dağ1lımla çalışabilmesi (basıklık ve çarpıklık değerlerinin -1 ile 1 arasında olması istenir [5]), modeli kurmak için ön şartlardan sadece modelin belirlenmesi ve tanımlanması gibi şartların istenmesi ve en önemlisi de çok karmaşık modelleri, biçimlendirici ve yansıtıcı ölçme modelleri dahil olmak üzere, analiz edebilmesi öne çıkan avantajlarındandır [15].
VT-YEM, gözlenen değişkenlerden yola çıkıp doğrudan gözlemlenemeyen değişkenler arasındaki ilişkileri açıklar [5]. VT-YEM, dışsal ölçme modeli ve içsel ölçme modeli olmak üzere iki k1sımdan oluşur. Dişsal ölçme modeli, gözlenen değişkenlerden hesaplanır ayrıca biçimlendirici (formative) ve yansitıcı (reflective) olmak üzere iki ölçme modelinden oluşur. Biçimlendirici ölçme modelinde oklar göstergeden yapıya doğrudur, yani göstergeler yapıya neden olur. Yans1tıcı ölçme modelinde (en yaygın kullanılan ölçme modelidir) ise oklar yapıdan göstergelere işaret eder yani, yap1 göstergelere sebep olur, dolayısıyla her bir göstergeye ait bir hata vardır (Şekil 1). VT-YEM, eğer bir regresyon gibi düşünülürse, içsel bağımsız değişkenlere eksojen ve içsel bağımlı değişkenlere ise endojen değişken denir.

VT-YEM, temelde iki aşamada çalışır: birinci aşamada dışsal ölçme modeli ağırlıkları/yükleri hesaplanır, ikinci aşamada ise yapısal yol katsayıları ve $\mathrm{R}^{2}$ hesaplanır. VT-YEM, alt çalışma aşamaları hesaba katılırsa toplam 7 adımda çalıŞ1r [16]:

Adım 1: Dışsal ölçme modellerinin (biçimlendirici ya da yansıtıcı) tüm keyfi ağırlıkların atanmas1

Adım 2: Gizil değişkenlerin değerlerinin dışsal modelden tahmininin hesaplanması

Adım 3: İç (yani yapısal ya da gizil) modelin ağırlıklarının elde edilmesi (gizli değişkenlerin birbirleriyle olan ilişkisi).

Adım 4: Gizli değişkenlerin iç tahminlerinin hesaplanmas

Adım 5: Dış modelin yeni ağırlıklarının hesaplanması

Ağırlıklar yakınsayana kadar Adım 2-5'i tekrarlanmasi

Adım 6: Yapısal modelin yol katsayılarını (ağırlikları) tahmin edilmesi

Adım 7: Dış ölçüm modeli için yükleri (ağırlıklar1) tahmin edilmesi

Bu çalıșmada modelleri analiz ve hipotezleri test etmek için SmartPLS 3 [17] paket programı kullanılmıştır. Modellerin değerlendirilmesi Hair ve 
ark.'na [10] göre yapılmıştır. VT-YEM metodunun kovaryans tabanlı YEM metodu gibi global uyum indisleri bulunmamakta fakat kendine özgü değerlendirme kriterleri vardır. Bu kriterler iki kısma ayrılır: birinci kısım ölçme modellerinin değerlendirilmesi (biçimlendirici ve yansıtıcı ölçme modelleri ayrı ayrı değerlendirilir), ikinci kısım ise yapısal modelin değerlendirilmesidir. $\mathrm{Bu}$ çalışmada sadece biçimlendirici ölçme modelleri kullanıldığından yansıtıcı ölçme modellerine ait değerlendirme kriterlerine yer verilmeyecektir.

Biçimlendirici (dışsal) ölçme modellerinin değerlendirilmesi:

-Varyans şişme faktörünün (Variance Inflation Factor-VIF) $<5$ olmas1

-Yakınsak geçerlilik için artıklık (redundancy) analizinin yapılması ve korelasyonun $\geqslant 0.70 \mathrm{ol}-$ mas1

-Bootstrap prosedürüne göre gösterge ağrılıklarının ilgili ve anlamlı olması istenir.

\section{Yapısal (içsel) modelin değerlendirilmesi}

-Eksojen (içsel bağımsız) değişkenlerin her bir endojen (içsel bağımlı) değişkeni belirleme katsayısı $\left(\mathrm{R}^{2}\right)$ ile açıklanan varyasyonun değerlendirilmesi sonucu elde edilen $\mathrm{R}^{2}$ değeri 0 ile 1 aralığında değişir ve $\mathrm{R}^{2}$ değerleri 0.75 önemli, 0.50 -orta ve 0.25-xayif olarak tanımlanmaktadır.

-Varyans şişme faktörünün (Variance Inflation Factor-VIF) $<3$ olmasi istenir VIF $<5$ de kabul edilir.

-Etki büyüklüğü $\left(f^{2}\right)$ 0.02-küçük, 0.15-orta ve 0.35-büyük olarak tanımlanır.

Son olarak, parametrik olmayan bootstrap prosedürü kullanılarak (yapısal) yol katsayıları, dışsal ağırlıklar, dışsa yüklerin anlamlılıkları $(\mathrm{p}<0.05)$ değerlendirilir. Tahmin edilen standart hata değerleri ile t istatistiği ( $>1.96)$ ve güven aralıklarının hesaplanması için parametrik olmayan bootstrap (yeniden örnekleme) kullanılır. Yeniden örneklemin 5000 olması tavsiye edilmektedir [5].

\section{Araştırma Bulguları}

\section{Yapısal eşitlik modelinin kestirilmesi}

VT-YEM modeli toplam 4 gizil değişken arasındaki 4 ilişkiyi tahmin etmiştir. Gizil değişkenler arasındaki ilişkiler Şekil 2'de verilmiştir. Çalışmanın tamamında, ilgili gizil değişkenler arasındaki ilişkilerin tahmin edilmesi için 7 tane gösterge kullanılmıştır. Tek göstergeli gizil değişkenler hariç ( $\mathrm{pH}$ ve su kalitesi) diğer gizil değişkenler biçimlendirici ölçüm modeline göre kurulmuştur. Sonuç olarak tüm ilişkilerin anlamlı olup olmadığ 1 bootstrap prosedürü ile 5000 alt örneklem oluşturularak hesaplanmıştır.

\section{Ölçme modellerinin değerlendirilmesi}

Bu çalışmada, VT-YEM tahminler için biçimlendirici ölçme modeli kullanılmıştır. VT-YEM modelinin birinci aşamaya ait tahmin sonuçları Tablo 2'de verilmiştir. KEEK-YEM yönteminde biçimlendirici ölçüm modellerinin değerlendirilmesinde, göstergeler arası korelasyondan kaynakl1, varyans şişme faktörü (VIF $<3$ istenir, $<5$ de olabilir) büyük rol oynamaktadır. Katyonlar gizil değişkenine ait $\mathrm{Mg}^{2+}$ ve $\mathrm{Na}^{+}$göstergelerin VIF değerleri aynı olup 1.02 olarak görülmektedir. Katyonlar değişkeni üzerinde $\mathrm{Mg}^{2+}$ ve $\mathrm{Na}^{+}$ göstergelerinin katkıları (ağırlıkları) sırasıyla 0.967 ve 0.421 olarak tahmin edilmiştir. Tablo 2'de gösterildiği gibi $\mathrm{Mg}^{2+}$ anlamlı oluğu halde $\mathrm{Na}^{+}$katkısı anlamlı görülmemektedir. Tablo

Tablo 1. Biçimlendirici ölçme modeli tahmin sonuçları

Table 1. Estimation results of formative measurement model

\begin{tabular}{lccccc}
\hline $\begin{array}{l}\text { Biçimlendirici } \\
\text { Ölçme Modeli }\end{array}$ & $\begin{array}{l}\text { Dış A Ă̆ırlıklar } \\
\text { (Dış Yükler) }\end{array}$ & t Değeri & $\begin{array}{l}\text { Önem } \\
(\mathbf{p}<\mathbf{0 . 0 5}) \text { ? }\end{array}$ & $\begin{array}{l}\text { 95\% Bootstrap } \\
\text { Güven Aralı̆̆ }\end{array}$ & VIF \\
\hline $\mathrm{Mg}^{2+}$ & $0.967(0.909)$ & 7.208 & Evet & {$[0.680,1.200]$} & 1.019 \\
$\mathrm{Na}^{+}$ & $0.421(0.289)$ & 1.508 & Hayır & {$[-0.124,0.798]$} & 1.019 \\
$\mathrm{Cl}^{-}$ & $0.660(0.942)$ & 1.753 & Evet & {$[-0.162,1.070]$} & 2.248 \\
$\mathrm{HCO}_{3}^{-}$ & $0.140(-0.146)$ & 0.513 & Hayır & {$[-0.313,0.547]$} & 1.100 \\
$\mathrm{SO}_{4}^{+}$ & $0.445(0.897)$ & 1.234 & Hayır & {$[-0.038,1.128]$} & 2.128 \\
\hline
\end{tabular}


2'deki bilgiler göz önüne alındığında, göstergelerin katyonlar gizil değişkenine olan tahmini etkisi sıralandığında $\mathrm{Mg}^{2+}(0.967)>\mathrm{Na}^{+}(0.421)$ olduğu görülmektedir.

Aynı şekilde, Anyonlar gizil değişkenine ait $\mathrm{Cl}^{-}$, $\mathrm{HCO}_{3}{ }^{-}$ve $\mathrm{SO}_{4}{ }^{+}$ölçümlerinin VIF değerleri sırasıyla $2.25,1.1$ ve 1.13 olduğu görülmektedir. $\mathrm{Cl}^{-}$, $\mathrm{HCO}_{3}{ }^{-}$ve $\mathrm{SO}_{4}{ }^{+}$ölçümlerinin Anyonlar değişkeni üzerindeki katkıları (ağırlıklar) sırasıyla 0.660, 0.140 ve 0.445 şeklinde kestirildiği görülmektedir. $\mathrm{SO}_{4}{ }^{+}$değişkenine ait ağırlık değeri (0.445) orta düzey olmasına rağmen anlamlı çıkmadığı görülmüştür. Anyonlar değişkenini etkileyen göstergelerden sadece $\mathrm{Cl}^{-}$değişkeninin anlamlı bir etkiye sahip olduğu, $\mathrm{HCO}_{3}{ }^{-}$ve $\mathrm{SO}_{4}{ }^{+}$değişkenlerinin ise anlamlı olmadığ 2 'de, aynı zamanda, güven aralıklarının tahminleri de verilmiştir.

\section{Yapısal modelin değerlendirilmesi}

Yapısal modelin hesaplanması (yol katsayılar1-

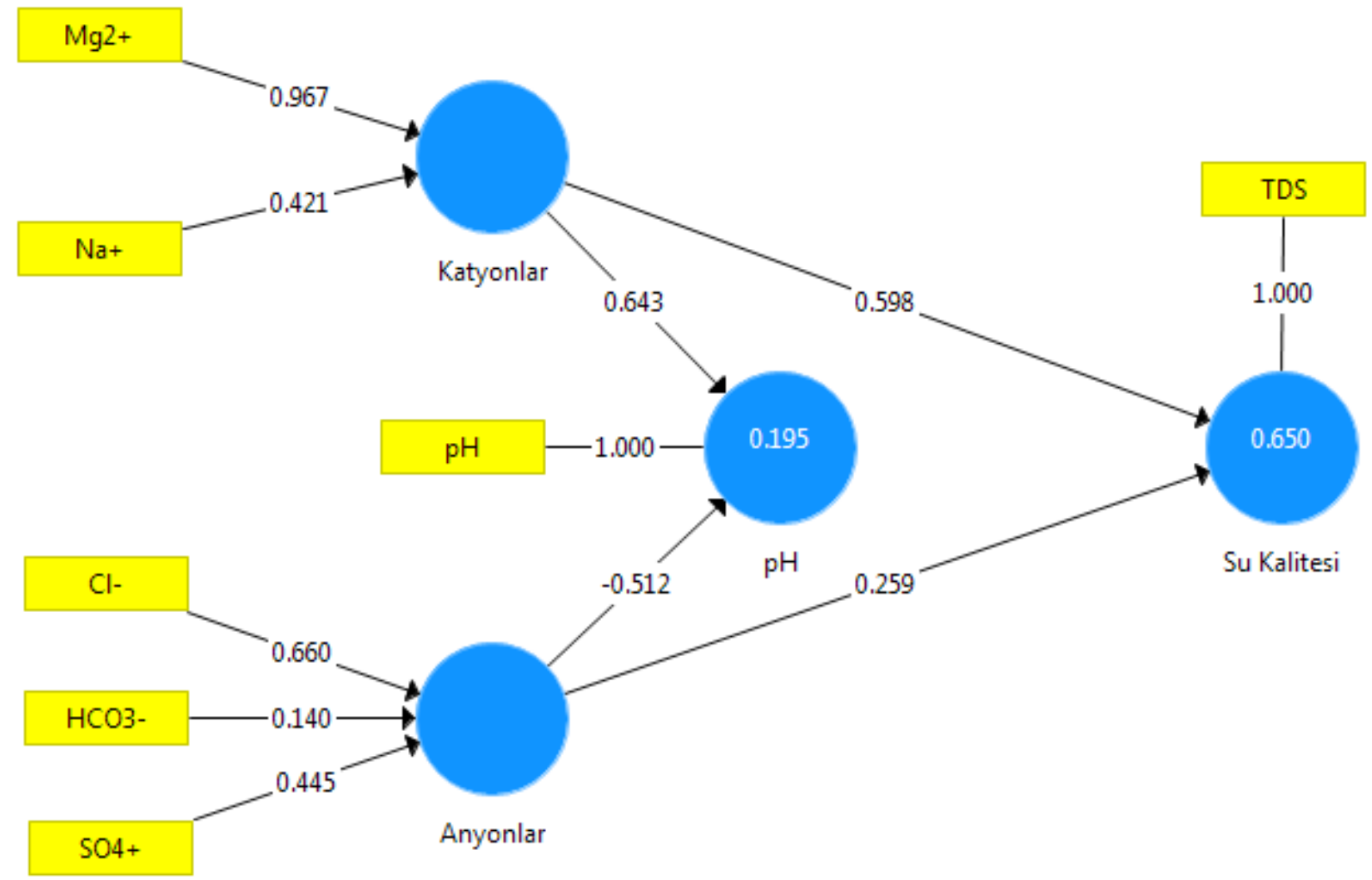

Şekil 2. Yer altı sularının yapısal eşitlik modeli ile hesaplanması. Yuvarlaklar gizil değişkenleri, kutucuklar ise ölçüm değişkenlerini (göstergeleri) ifade etmektedir. Gizil değişkenler arasındaki ilişkiler oklarla (yol katsayıları) gösterilmiștir. Yuvarlaklar ve kutucuklar arasındaki oklar ise ăgrılıkları (biçimlendirici ölçme modelinde hesaplanır) göstermektedir. Yuvarlaklar (sadece endojen değişkenler için hesaplanır) içindeki rakamlar belirleme katsayısını $\left(R^{2}\right)$ ifade eder. Şekil l'deki şekil sadece genel yapısal eşitlik modeli şemasını ifade eder. Şekil 2 ise gizil değişkenler ve bunlarla ilişkili olan ölçüm değişkenlerini göstermektedir.

Figure 2. Calculation of groundwater using structural equation model. Circles represent latent variables, and squares represent measurement variables (indicators). The relationships between latent variables are shown by arrows (path coefficients). The arrows between the circles and boxes show the weight (calculated in the formative measurement model). Numbers in circles (calculated only for endogenous variables) represent the coefficient of determination $\left(R^{2}\right)$. The figure in Figure 1 only expresses the general structural equation model scheme. Figure 2 shows the latent variables and the measurement variables associated with them. 
nın vs.) ikinci adımda gerçekleşir (Şekil 2). Toplam 4 gizil değişkene ait 4 yol katsayısından 3'ü anlamlı $(\mathrm{p}<0.05)$ bulunmuştur (Tablo 3$)$. Tüm değişkenler için VIF değeri 2.135, yani gizil değişkenler arasında ortak bağlantı probleminin olmadığı söylenebilir [5]. Katyonlar değişkeninin ve anyonlar değişkeninin su kalitesi değişkeni üzerindeki yol katsayıları anlamlı olup $(\mathrm{p}<0.05)$ sirasiyla 0.598 ve 0.259 ; $\mathrm{pH}$ üzerindeki yol katsayıları ise sirasiyla $0.598(\mathrm{p}<0.05)$ ve $(-0.402)$ olarak tahmin edilmiştir. Katyonlar değişkeninin su kalitesi ve $\mathrm{pH}$ üzerindeki etkileri Anyonlar değişkeninden daha yüksek olduğu görülmüştür. pH ve su kalitesi açısından etki büyüklüklerinin katyonlar değişkeni için sırasıyla orta ve üzeri; Anyonlar değişkeni için ise ortaya yakın ve orta olarak sonuçlanmıştır.

Belirleme katsayısı $\left(\mathrm{R}^{2}\right)$ için sonuçlar şu şekildedir: model, $\mathrm{pH}$ 'deki varyansin 0.195 'ini, su kali- çalışmada yansıtıcı ölçme modeli kullanılmadığ için bu modelle ilgili kriterlere değinilmemiştir. Yapısal eşitlik modelleri ölçüm modeli ve yapısal model olmak üzere iki kısma ayrıldığı için bulgular kısmında olduğu gibi bu kısımda da ayrı ayrı incelenmiştir.

\section{Ölçme modelinin değerlendirilmesi}

Yapısal eşitlik modellerinde yansitıcı model ile biçimlendirici model arasında cetvelle ayrılacak bir ayrımın olmadığı bildirilmiştir [5]. Bunu belirlemek için alanyazında yayınlanmış çalışmalara odaklanılması gerektiği belirtilerek nihayetinde literatür ve uzman bilgisi eşliğinde modelin belirlenebileceği ifade edilmiştir [5]. Literatüre bakıldığında mevcut çalışmada biçimlendirici ölçme modelini kullanmanın uygun olabileceği düşünülmüştür. Çünkü, belirtilen göstergeler ait oldukları yapıları oluşturmaktadır. Bu açıdan düşünüldüğünde en uygun ölçme modelinin biçim-

Tablo 2. Yapisal modele ait tahmin sonuçları

Table 2. Estimation results of the structural model

\begin{tabular}{llccccc}
\hline Yapılar & & Yol katsayıları & $\begin{array}{l}\text { 95\%bootstrap } \\
\text { güven aralıkları }\end{array}$ & $\begin{array}{c}\text { Önem } \\
(\mathbf{p}<\mathbf{0 . 0 5}) \boldsymbol{?}\end{array}$ & $\boldsymbol{f}^{2}$ Değeri & VIF \\
\hline \multirow{2}{*}{ Katyonlar } & $\rightarrow \mathrm{pH}$ & 0.643 & {$[-1.317,-0.112]$} & Evet & 0.241 & 2.135 \\
& $\rightarrow$ su kalitesi & 0.598 & {$[-0.110,0.419]$} & Evet & 0.478 & 2.135 \\
\multirow{2}{*}{ Anyonlar } & $\rightarrow \mathrm{pH}$ & -0.512 & {$[0.142,1.072]$} & Hayır & 0.152 & 2.135 \\
& $\rightarrow$ su kalitesi & 0.259 & {$[0.395,0.793]$} & Evet & 0.089 & 2.135 \\
\hline
\end{tabular}

tesindeki varyansın $0.65^{\prime}$ ini açıklamıştır. $\mathrm{pH}$ için açıklanan varyansın zayıf, su kalitesi için açıklanan varyansın yüksek olduğu görülmektedir. Böylece modelde, katyonlar ve anyonlar su kalitesi varyansını $\mathrm{pH}$ 'nin varyansına kıyasla yaklaşık 4 katı daha fazla oranda açıklamıştır.

\section{Tartışma}

SmartPLS 3, gösterge ağırlıkları/yükleri, yapı geçerliliği (composite relability-CR), açıklanan ortalama varyans (average variance extractedAVE), yol katsayıları, fornell-larcker kriteri, çapraz yükler, korelasyonların heterotrait-monotrait oranı (HTMT), varyans şişme faktörü (VIF) (hem göstergeler hem de yapılar için), t-değeri ve p-değerini ve daha fazlasını rapor eder. Şekil 2'de görüldügü gibi 2 yapı ve bu yapılara ait sekiz göstergeli teorik bir model oluşturulmuş ve modelin testi için SmartPLS ile analiz edilmiştir. $\mathrm{Bu}$ lendirici ölçme modeli olabileceği kararına varılmıştır. Sonuç olarak, yapısal eşitlik modellerinde biçimlendirici ölçme modellerinin deneysel çalışmalar için daha uygun olduğu bildirilmiştir [12].

Mevcut çalışmada gizil değişkenler için istenilen kriterlerin yerine getirildiği görülmüştür. Katyonların $\mathrm{Mg}^{2+}, \mathrm{Na}^{+}$ve daha birçok değişkenden meydana literatürde mevcuttur. Bu çalışmada uyum indislerini $\mathrm{Mg}^{2+}$ ve $\mathrm{Na}^{+}$sağladığı için katyonlar gizil değişkenini meydana getiren göstergeler olarak seçilmiștir. Bu çalıșmaya göre, Katyonlar değişkeni üzerinde $\mathrm{Mg}^{2+}(0.967)$ göstergesinin $\mathrm{Na}^{+}(0.421)$ göstergesinden daha fazla etkiye sahip olduğu görülmektedir. Bununla birlikte $\mathrm{Mg}^{2+}$, yapı üzerinde anlamlı $(\mathrm{p}<0.05)$ bir gösterge iken $\mathrm{Na}^{+}$anlamlı olmaya yakın $(p=0.066)$ bir tahmin gerçekleştirmiştir. Buna rağmen $\mathrm{Na}^{+}$'nın yapı üzerindeki etkisi anlamlı 
görünmese de ağırlık katsayısı 0.421 olarak bulunmuştur. $\mathrm{Mg}$ genel olarak yeraltı sularında $\mathrm{Na}^{+}$ya kıyasla sıralama yönünden daha az başat durumdadır [18], [19]. Buna rağmen yeraltı sularının kimyasal özellikleri ve kalite parametrelerinin seviyeleri su kaya interaksiyonları ve iyon değişim proseslerinden ve diğer antopojenik faktörlerin kontrolü altında olduğu bilinmektedir [1]-[3].

Anyonlar değişkenine gelindiğinde, bu yapıyı $\mathrm{Cl}^{-}, \mathrm{HCO}_{3}{ }^{-}$ve $\mathrm{SO}_{4}{ }^{+}$'ün oluşturduğu görülmektedir. Modelde, örneklem alınan bölge için anyonlar değişkenine $\mathrm{Cl}^{-}$göstergesinin anlamlı bir şekilde ve $\mathrm{HCO}_{3}{ }^{-}$ve $\mathrm{SO}_{4}{ }^{+}$'ten daha fazla katkı sağladığ 1 tahmin edilmiştir. $\mathrm{Cl}^{-}$'nin daha etkili olması $\mathrm{Cl}^{-}$un genel olarak yeraltı sularında anyonlar arasında en başat anyon olarak gösterilmesi ile açıklanabilir [18], [19]. Su örneklerindeki yüksek $\mathrm{Cl}^{-}$genel olarak kirlilik indeksi olarak düşünülmüş ve yer altı sularında kirliliğin takip edilmesinde bir izlence olarak ele alınmıştır [20]. Ayrıca ilgili yapı üzerinde $\mathrm{SO}_{4}{ }^{+}$ün $\mathrm{HCO}_{3}{ }^{-}$'ten daha etkili olduğu ama iki göstergenin de anlamlı olmadığ1 $\quad(\mathrm{p}>0.05) \quad$ kestirilmiştir. $\quad \mathrm{SO}_{4}{ }^{+}$ün $\mathrm{HCO}_{3}{ }^{-}$ten daha fazla etkili olmasinın sebebi $\mathrm{SO}_{4}{ }^{+}$'ün katyonlar grubunda daha etkili olan $\mathrm{Mg}^{2+}$ ile oluşturabileceği $\mathrm{MgSO}_{4}$ tuzlarının varlığı olabilir. Bu çalışmada uygulanan yapısal eşitlik modelinin doğrudan ölçülemeyen yapıların tutarlı bir şekilde ölçülebileceğini ortaya koymuştur.

\section{Yapısal modelin değerlendirilmesi}

Kovaryans tabanlı yapısal eşitlik modelinde (CB-YEM) gizil değişkenler en az iki gösterge ile ölçülebilirken kısmi en küçük kareler tabanlı YEM yönteminde gizil değişkenler bir gösterge (single item) ile ölçülebilmektedir [5]. Ayrıca bir yapı ne kadar çok göstergeye sahipse ilgili modelin kapsamı daha da artacak ve dolayısıyla elde edilecek bilgi, tahmin edilecek parametre ve elbette modelin karmaşıklığı da artacaktır. CBYEM çok kompleks modellerde kisitlı bir modele dönüşebilir ama VT-YEM için model ne kadar karmaşık olursa o kadar iyi tahmin yapılacaktir [5].

$\mathrm{Bu}$ modelde yapıların birbiriyle ilişkisi oldukça tutarlı görünmektedir. Yol katsayıları açısından Katyonlar değişkeninin $\mathrm{pH}$ üzerinde pozitif anlamlı bir katkısı $(\gamma=0.598)$ görülürken anyonlar değişkeninin negatif anlamlı bir etkisinin $(\gamma=$ 0.402) olduğu tahmin edilmiştir. Su ile katyonların teması neticesinde su moleküllerindeki pozitif yüklü $\mathrm{H}$ iyonlarının katyonlarla yer değiştirmesi ve $\mathrm{OH}$ iyonlarının ortamda çoğalması neticesinde $\mathrm{pH}$ oranında yükselmelerin oluşması ile açıklanabilir. Ayrıca bu modele göre $\mathrm{pH}$ üzerinde katyonların anyonlardan katsayıca daha etkili olduğu görülmüsstür. Buda örnekleme alanı, örnek sayıs1, örnekleme zamanı ve kirletici etmenlerin farklılığına göre değişim gösterebilir. pH değerleri su içerisinde yer alan toksik bileşiklerin yanısira suyun biyolojik ve kimyasal parametrelerinden de etkilenir. Ek olarak katyonlar ve anyonlar değişkenlerinin $\mathrm{pH}$ değişkenini \%19.5 $\left(\mathrm{R}^{2}\right)$ açıkladığı tahmin edilmiştir.

Su kalitesi üzerinde (temel yol modeli ile) farklı YEM çalışmaları bulunmaktadır [13], [21] fakat bu çalışmada gizil değişkenlere sahip bir modelin olması alan yazına daha fazla katkı sağlayacağı düşünülmektedir. Su kalitesini ölçmek için birçok parametre bulunmasına rağmen bu çalışma kapsamında toplam çözünmüş katı maddeler (TDS) göstergesi YEM kriterlerini sağladığı için modele katılmıştır. TDS su kalitesini ölçmede kullanıldığı için bu göstergenin ait olduğu yapıya su kalitesi adı verilmiştir.

$\mathrm{Su}$ kalitesini katyonlar anyonlar ve daha birçok değişkenin etkilediği açıktır [13]. Bununla birlikte bu çalışma kapsamında mevcut verilere göre su kalitesi bir yapı olarak değerlendirilmiştir. Model tahminlerine göre katyonlar $(\gamma=0.598)$, anyonlardan $(\gamma=0.259)$ daha fazla su kalitesini etkilemiştir. Ayrıca katyonların pH yol katsayısı su kalitesi yol katsayısından daha yüksek, anyonların da mutlak değerce aynı şekilde yüksek olduğu tahmin edilmiştir. Ek olarak, model tahminlerine göre katyonlar ve anyonlar yapılarının su kalitesine ait varyansın \%65'ini açıkladığı görülmüştür. Bu modelde sadece doğrudan yani eksojen değişkenlerin endojen değişkenler üzerinde tek yolla etkileri vardır. Bunlar katyonlar ve anyon- 
lar değişkenlerinin $\mathrm{pH}$ ve su kalitesi üzerine etkileridir. YEM sonuçlarına göre regresyon eşitliği gibi eşitlikler yazılabilir [22]. Bağımsız anyonlar ve katyonlar değişkenlerinin bağımlı $\mathrm{pH}$ ve su kalitesi değişkenleri üzerindeki etkilerine ait eşitlikler Eşitlik 1 ve 2'deki gibi verilebilir (K: Katyonlar, A: Anyonlar):

\section{Eşitlik 1:}

$\mathbf{p H}=-0.00002+(0.643) * \mathbf{K}+(-0.512) * \mathbf{A}$

\section{Eşitlik 2:}

Su Kalitesi $=0.00004+(0.598) * \mathbf{K}+(0.259) * \mathbf{A}$

Burada hem $\mathrm{pH}$ hem su kalitesi üzerinde tahmin dilen katyonlar regresyon katsayılarının anyonlar katsayılarına nispeten yüksek olduğu görülmektedir.

\section{Sonuç ve Öneriler}

YEM modelleri, gösterge-gösterge, göstergeyap1, yapı-yapı arasındaki ilişkileri korelasyonel ve regresyonel incelemesi açısından önemlidir. $\mathrm{Bu}$ çalışmada katyonların ve anyonların $\mathrm{pH}$ ve su kalitesi arasındaki ilişkilere bakılmıştır. Mevcut çalışmada, doğrudan ölçülemeyen değişkenlerin diğer bir ifadeyle sözel değişkenlerin birbiri arasındaki ilişkilerin incelenmesi açısından önem arz etmektedir.

Mevcut çalışmada gösterilen metodolojinin, hidrokimyasal bilgiler (değişkenler) arasındaki tüm olası etkileşimleri dikkate alan istatistiksel bir modele dahil etmeye izin verdiği görülmektedir. Model, hidrokimyasal değişkenlerin istatistiksel entegrasyonunu sunarak daha sağlam bir yorumlama sağlar. Araştırma, yer altı suyu kalitesini araştırmayı amaçlamaktadır. İncelenen akiferdeki hidrokimyasal varyasyonu kontrol eden süreci tanımlamak mümkündür. Ayrıca önerilen metodoloji, hidrokimyasal verilerin mevcut olduğu birçok tipik akiferde faydalı olabilir. Gösterilen yaklaşım, çalışmanın sonuçlarının yalnızca kavramsal modeldeki değişkenler arasında önerilen ilişkilerin örnek veri tarafindan desteklendiği sınırlamasını sergilemektedir. Uyum in- deksleri, nispeten küçük örneklem boyutu olmasına rağmen verilerin çok iyi bir YEM uyumu gösterdiği anlaşılmaktadır. Gelecek çalışmalarda daha fazla gösterge ile daha fazla yapının birbiriyle ilişkileri, su kalitesi gibi kavramlar üzerindeki etkileri incelenebilir.

\section{Kaynaklar}

[1] M. İ. Yeşilnacar et al., "Geomedical assessment of an area having high-fluoride groundwater in southeastern Turkey," Environmental Earth Sciences, vol. 75, no. 2, p. 162, Jan. 2016, doi: 10.1007/s12665-015-5002-6.

P. Sahu, G. C. Kisku, P. K. Singh, V. Kumar, P. Kumar, and N. Shukla, "Multivariate statistical interpretation on seasonal variations of fluoridecontaminated groundwater quality of Lalganj Tehsil, Raebareli District (UP), India," Environmental Earth Sciences, 2018, doi: 10.1007/s12665-018-7658-1.

[3] İ. Yolcubal, Ö. C. Ataş Gündüz, and N. Kurtuluş, "Origin of salinization and pollution sources and geochemical processes in urban coastal aquifer (Kocaeli, NW Turkey)," Environmental Earth Sciences, 2019, doi: 10.1007/s12665-019-8181-8.

[4] H. Wold, "Quantitative sociology," in International Perspectives on Mathematical and Statistical Modeling, H. M. Blalock, Ed. New York: Seminar Press, 1975, pp. 307-357.

[5] J. Hair, G. Hult, C. Ringle, and M. Sarstedt, $A$ Primer on Partial Least Squares Structural Equation Modeling (PLS-SEM). Thousand Oaks: SAGE, 2017.

[6] J. Hair, C. M. Ringle, and M. Sarstedt, "PLSSEM: Indeed a Silver Bullet," Journal of Marketing Theory and Practice, vol. 19, no. 2, pp. 139-152, Apr. 2011, doi: 10.2753/MTP10696679190202

[7] M. Sarstedt, C. M. Ringle, and J. Hair, "Partial Least Squares Structural Equation Modeling," in Handbook of Market Research, Cham: Springer International Publishing, 2017, pp. 1-40.

[8] R. G. Lomax, "The Effect of Measurement Error in Structural Equation Modeling," The Journal of Experimental Education, vol. 54, no. 3, pp. 157162, Apr. 1986, doi: 10.1080/00220973.1986.10806415.

[9] W. W. Chin and P. R. Newsted, "Structural equation modeling analysis with small samples using partial least squares," in Statistical strategies for small sample research, R. H. Hoyle, Ed. Thousand Oaks: Sage Publications, 1999, pp. 
$307-341$

[10] J. Hair, J. J. Risher, M. Sarstedt, and C. M. Ringle, "When to use and how to report the results of PLS-SEM," European Business Review, vol. 31, no. 1, pp. 2-24, Jan. 2019, doi: 10.1108/EBR-11-2018-0203.

[11] J. Hair, C. L. Hollingsworth, A. B. Randolph, and A. Y. L. Chong, "An updated and expanded assessment of PLS-SEM in information systems research," Industrial Management \& Data Systems, vol. 117, no. 3, pp. 442-458, Apr. 2017, doi: 10.1108/IMDS-04-2016-0130.

[12] V. S. Rodrigues, R. F. do Valle Júnior, L. F. Sanches Fernandes, and F. A. L. Pacheco, "The assessment of water erosion using Partial Least Squares-Path Modeling: A study in a legally protected area with environmental land use conflicts," Science of the Total Environment, vol. 691, pp. 1225-1241, 2019, doi: 10.1016/j.scitotenv.2019.07.216.

[13] N. C. Viswanath, P. G. D. Kumar, and K. K. Ammad, "Statistical Analysis of Quality of Water in Various Water Shed for Kozhikode City, Kerala, India," Aquatic Procedia, vol. 4, pp. 1078-1085, 2015, doi: 10.1016/j.aqpro.2015.02.136.

[14] H. Wold, Model Construction and Evaluation When Theoretical Knowledge Is Scarce. Theory and Application of Partial Least Squares. Academic Press, 1980.

[15] S. Akter, S. Fosso Wamba, and S. Dewan, "Why PLS-SEM is suitable for complex modelling? An empirical illustration in big data analytics quality," Production Planning \& Control, vol. 28, no. 11-12, pp. 1011-1021, Sep. 2017, doi: 10.1080/09537287.2016.1267411.
[16] D. Ghosh, A. Olewnik, and K. Lewis, "Application of autoencoders in cyber-empathic design," Design Science, vol. 4, pp. 1-17, 2018, doi: $10.1017 / \mathrm{dsj} .2018 .11$.

[17] C. M. Ringle, S. Wende, and J.-M. Becker, "SmartPLS 3." SmartPLS GmbH, 2015.

[18] M. I. Yesilnacar and I. Yenigun, "Effect of irrigation on a deep aquifer: a case study from the semi-arid Harran Plain, GAP Project, Turkey," Bulletin of Engineering Geology and the Environment, vol. 70, no. 2, pp. 213-221, May 2011, doi: 10.1007/s10064-010-0299-6.

[19] D. Marghade, D. B. Malpe, and A. B. Zade, "Geochemical characterization of groundwater from northeastern part of Nagpur urban, Central India," Environmental Earth Sciences, vol. 62, no. 7, pp. 1419-1430, Apr. 2011, doi: 10.1007/s12665-010-0627-y.

[20] M. Loizidou and E. Kapetanios, "Effect of leachate from landfills on underground water quality," The Science of The Total Environment, vol. 128, no. 1, pp. 69-81, Jan. 1993, doi: 10.1016/0048-9697(93)90180-E.

[21] I. Chenini and S. Khemiri, "Evaluation of ground water quality using multiple linear regression and structural equation modeling," International Journal of Environmental Science and Technology, 2009, doi: 10.1007/BF03326090.

[22] V. Esposito Vinzi, W. W. Chin, J. Henseler, and H. Wang, Handbook of Partial Least Squares. Berlin, Heidelberg: Springer Berlin Heidelberg, 2010. 